\title{
Singapore First Aid Guidelines 2021
}

\author{
Faraz Zarisfi ${ }^{1}$, MRCSEd, fRCEM, Jen Heng ${\underline{P e k^{2}}}$, MMed, MCEM, Janice Hui Hong $\underline{O h}^{3}$, BSc, Jun Hao Loke ${ }^{4}$, BSc,
} Swee Han $\underline{\mathrm{Lim}}^{1}$, FRCSEd, FRCPEd

\begin{abstract}
The Singapore Resuscitation and First Aid Council is updating the guidelines for first aid based on the latest evidence-based review from the International First Aid Taskforce Consensus on Science with Treatment Recommendations published in 2020. This is part of the regular updating of standards of care and training for first aid. This article presents some of the updated evidence-based approaches to first aid treatments in common emergencies such as asthma, chronic bronchitis, anaphylaxis, shock, unresponsiveness, seizure, heat disorders, ingested poisons, bleeding, head and spinal injury, bites and dental injuries. These updated treatments will be incorporated into the Standard and Child First Aid course syllabus in Singapore.
\end{abstract}

Keywords: first aid, injuries, recovery position, safety, shock

\section{INTRODUCTION}

The Singapore Resuscitation and First Aid Council (SRFAC) has set an ambitious vision for every Singaporean to have the competence to provide first aid when required. Part of this mission involves making regular updates to the practice standards based on the latest international scientific consensus. These updates occur every five years under the auspices of the First Aid Taskforce of the International Liaison Committee on Resuscitation (ILCOR). Specific topics are reviewed by the Taskforce, leading to the publication of the Consensus on Science with Treatment Recommendations, the latest of these being in 2020. We take this opportunity to re-emphasise some basic concepts and highlight some of the clinical evidence-based changes in practice that will be implemented in the first aid standards set out by SRFAC. In regular practice, the most important changes include the use of the recovery position, management of severe bleeding and management of casualties with heatstroke. We expect first aiders and instructors to familiarise themselves with these changes, which will be reflected in the changed curriculum available later this year.

\section{KEY PRINCIPLES}

\section{The practice of first aid}

First aid, as defined by the 2020 ILCOR First Aid Task Force, is the behaviour and initial care provided to help and support an acute illness or injury. ${ }^{(1)}$ It can be initiated by anyone to preserve life, alleviate suffering, limit further injury and promote recovery in any situation. A first aider needs to be proficient in first aid skills. ${ }^{(2)}$ As a minimum, this should include: (a) early recognition, assessment and prioritisation of the need for first aid; (b) provision of care with appropriate knowledge, skill and behaviour; and (c) awareness of limitations and seeking additional help without delay.

\section{Safety}

Scene safety is paramount for professional Emergency Medical Service (EMS) practitioners, ${ }^{(3)}$ as it is for any first aiders. One should never underestimate the importance of situational awareness.
Upon arrival at site, the first aider should always ensure safety before proceeding to assist the casualty. An injured first aider will be of no help to a casualty, and thus, it pays to be extra cautious and to mindfully conduct a scene survey before a first aider proceeds further. Examples of an unsafe rescue scene may include slippery, wet or contaminated surfaces; active mains or grid electricity; road traffic incidents where the road is still open to traffic, or has an oil spill or burning vehicle; or a fall from a height where there are additional falling objects or persons.

Once the first aider has ascertained that the scene is safe, with no obvious or potential threats, he/she may proceed with care. However, should there be noticeable or potential hazards that cannot be mitigated, the first aider should stay away while concurrently activating the EMS for a quicker response, as time is crucial to ensure survivability of a casualty. In some instances, the first aider may recognise windows of opportunity for the casualty to be moved to a safer location prior to treatment, but this should not be attempted if the movement could potentially worsen the condition of the casualty.

The impact of the COVID-19 pandemic has highlighted the need for a strong emphasis on infection control principles. Proper personal protective equipment (PPE) should be used whenever possible. Universal precautions, such as avoiding the transfer of body fluids, should be exercised to minimise unnecessary exposure and harm to the first aider. While PPE may not be readily available to first aiders, the following should be practised whenever possible: (a) wash hands with water and soap (or alcohol/disinfectant hand rub) before and after attending to the casualty; (b) wear gloves, face mask, eye protection and/or full gown if there is a potential risk of coming in contact with blood or other body fluids or tissues; and (c) safely dispose of all contaminated items after use.

\section{First aid kit}

A first aid kit contains supplies and equipment that may be used when administering first aid. As the kit may be tailored according

${ }^{1}$ Department of Emergency Medicine, Singapore General Hospital, ${ }^{2}$ Department of Emergency Medicine, Sengkang General Hospital, ${ }^{3}$ Emergency Medical Services Department, Singapore Civil Defence Force, ${ }^{4}$ Singapore Resuscitation and First Aid Council Unit for Pre-hospital Emergency Care, Singapore

Correspondence: DrFaraz Zarisfi, Consultant, Department of Emergency Medicine, Singapore General Hospital, Outram Road, Singapore 169608. faraz.zarisfi@singhealth.com.sg 
to individual or organisational needs, the contents may vary widely. We recommend that every home and workplace be equipped with a first aid kit containing the following basic items: $20 \mathrm{~mL}$ of sterile water or saline in disposable vials; adhesive dressings (woven, non-woven or transparent); absorbent gauze; eye pads; crepe bandage $(5 \mathrm{~cm}, 10 \mathrm{~cm}, 15 \mathrm{~cm})$; triangular bandages; hypoallergenic tape; safety pins; tweezer; scissors; pen-light; antiseptic wipes; and disposable gloves. Supplementary supplies such as eye shields, splints, digital thermometer and a resuscitation mask or face shield can be considered for inclusion (Fig. 1). Additional items such as commercial tourniquets, haemostatic and burns dressings, digital blood pressure monitor, pulse oximeter, and glucose meter may be included depending on the purpose of use for specialised first aid kits. However, additional training must be available if the first aider is expected to use the specialised equipment.

All first aid kits should be recognisable, clearly marked and immediately mobile (i.e. not locked up or fixed to a wall). The contents should be checked regularly (as indicated by the workplace or regulating authorities), and used or expired items should be replaced early. For workplaces and special events, the quantity of each item in the first aid kit depends on the number of casualties the organisation expects to cater for, with careful consideration of the activities and environment where anticipated injuries or illnesses may occur. First aid kits meant for schools or workplaces should ideally not contain medication due to allergy concerns. Moreover, first aiders are trained to administer first aid and are not trained to make decisions on the type of medication to be given for different conditions or ailments. Where recommendations are given below on the administration of medicines, the first aider is not expected to have a supply of the medicines, but rather an awareness of when and how to administer the casualty's own supply. Some workplaces and schools will, however, have specially trained personnel or healthcare providers on site to administer medications if required.

\section{MEDICAL URGENCIES Breathing difficulties/asthma and chronic obstructive pulmonary disease}

Casualties with asthma or chronic obstructive pulmonary disease may experience breathing difficulty due to acute exacerbation of these conditions. Proper use of inhaled bronchodilators can effectively relieve symptoms, with low incidence of adverse events. ${ }^{(4-14)}$ First aiders should, therefore, be trained in the administration of bronchodilators in order to assist when required. ${ }^{(15,16)}$ There remains no evidence for or against routine administration of supplementary oxygen by first aiders, and as oxygen is not always available and specific training in its use is required, we do not consider it a standard first aid skill. ${ }^{(17-20)}$

\section{Anaphylaxis}

First aiders should be trained in the recognition and first aid management of anaphylaxis. ${ }^{(1)}$ If available, first aiders should assist with the administration of adrenaline autoinjector, which may be carried by persons at risk. ${ }^{(15,16,21)}$ The EMS should be activated subsequently. If the reaction is severe and there is no response after 5-15 minutes of the first injection, or there is a recurrence of severe symptoms, a second adrenaline autoinjector may be administered. ${ }^{(1)}$

\section{Chest pain}

The causes of chest pain may vary from self-limiting conditions with no long-term sequelae to those that are imminently lifethreatening. Differentiating them is difficult; although recognised patterns of disease presentation exist, there is enough variation in presentation to challenge even the most experienced of practitioners. The transfer of anyone with chest pain to a healthcare facility should be performed by the EMS and not via private transport. Aspirin (300 mg) can be administered as soon as possible in casualties with chest pain due to suspected myocardial infarction, as this has been shown to decrease morbidity and mortality. ${ }^{(1,22-24)}$ However, if the cause of chest pain is unclear or due to trauma and the casualty has drug allergy or contraindication such as severe asthma or known gastrointestinal bleeding, then administration of aspirin should be deferred to the EMS or a doctor.

\section{Shock}

Based on consensus review of the evidence, first aiders should place persons with shock in the supine position rather than the upright position. ${ }^{(1)}$ Passive leg raise of the feet to angles of $30^{\circ}-60^{\circ}$ from the supine position may briefly improve blood pressure. This manoeuvre can be considered while awaiting the arrival of the EMS, unless the movement causes pain. ${ }^{(25,26)}$ Head down (Trendelenberg) positioning should not be attempted by first aiders, as there is a risk of respiratory compromise. ${ }^{(27)}$

\section{Recovery position in unresponsive casualties}

If a casualty is unresponsive and not breathing normally, the first aider should proceed immediately according to the basic life support guidelines. ${ }^{(28)}$

For cardiac arrest casualties who have regained spontaneous breathing and circulation after life support measures, SRFAC does not recommend placing the casualty in the recovery position, as it may hinder the detection of subsequent loss of cardiac output. They should be placed in a supine position and monitored continuously by the first aiders.

If a neck, back, hip or pelvic injury is suspected, casualties should be left in the position in which they were found to avoid further potential injury, unless there is a need to open the airway or to reach a safe location. An unresponsive casualty who has spontaneous breathing but is affected by conditions that are noncardiac arrest in nature, such as stroke, hypoglycaemia or fainting, should be positioned in a lateral, side-lying recovery position as opposed to the supine position, ${ }^{(1)}$ ideally facing the first aider.

When the casualty is lying supine, the recovery position ${ }^{(29)}$ can be achieved with the following steps:

1. Abduct the arm of the nearer shoulder to $90^{\circ}$, with the elbow flexed at $90^{\circ}$ and the palm facing upwards (like taking an oath). 


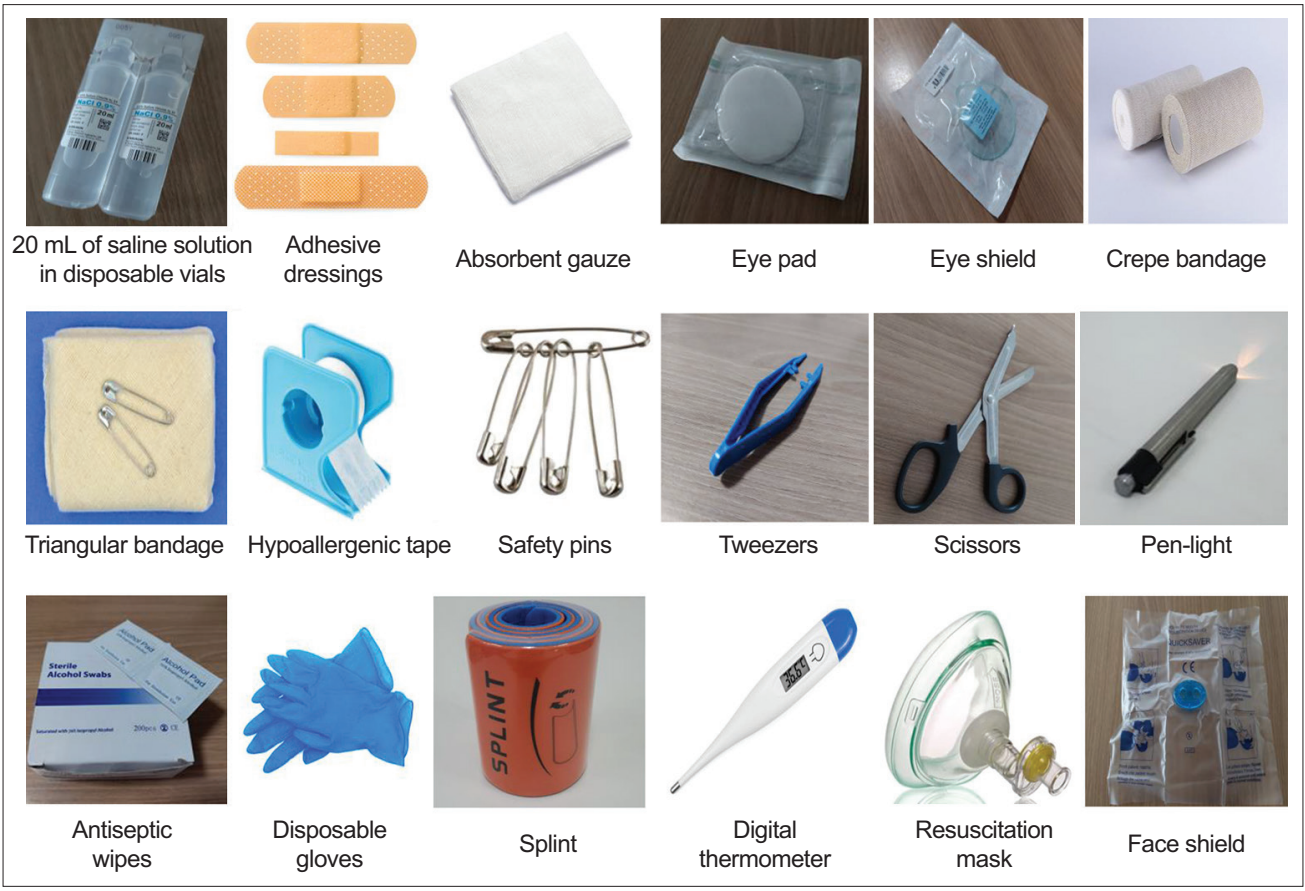

Fig. 1 Photograph shows the items in a first aid kit.

2. Place the farther hand across the body and place the back of the palm against the casualty's cheek nearer to the first aider.

3. Flex the farther knee to $90^{\circ}$.

4. While keeping the casualty's back of hand pressed against the casualty's cheek, pull the farther thigh and roll the casualty towards the first aider, and the casualty will be lying on his/her side.

5. Adjust the lower limb on top so that both the hip and knee are flexed at $90^{\circ}$.

6. Tilt the head back to keep the airway open.

It is important to stay with the casualty and monitor the breathing and level of consciousness in case of further deterioration that may go unrecognised. ${ }^{(30)}$

\section{Seizure}

While the majority of seizures are self-limiting events in the context of casualties with epilepsy, a small number of casualties with cardiac arrest will initially develop anoxic seizures. Some casualties with epilepsy may also develop cardiac arrest during a seizure. ${ }^{(31,32)}$ The first aider will need to check for normal breathing after seizures have stopped, and start cardiopulmonary resuscitation and use an automated external defibrillator if breathing is not present.

During a seizure, the first aider's goal is to ensure airway patency and to prevent injury. ${ }^{(21,32)}$ The casualty should be carefully kept in a left lateral position. ${ }^{(33)}$ Avoid placing any object in the casualty's mouth, as it can cause dental damage or aspiration. Unnecessary use of restraint during a seizure may result in musculoskeletal injury. Activate the EMS and continue to monitor the casualty, who may be unresponsive or confused for some time after the seizure.

\section{Heat disorders}

Heat cramps, heat exhaustion and heatstroke form a spectrum of illness associated with either physical activity or passive exposure in the presence of heat and humidity.

Heat cramps are involuntary muscle spasms after or during exercise. They are thought to be caused by a combination of muscular fatigue and water and electrolyte imbalance. Single or multiple muscle groups may be affected. First aid measures include rest, stretching the affected muscles, drinking a carbohydrate-electrolyte solution (such as juice, milk) or tap water, and icing. ${ }^{(2,34-43}$

Casualties with heat exhaustion may present with nausea, dizziness, muscle cramps, headache, fatigue and heavy sweating. Cooling measures should be initiated by moving the casualty to a cool place, removing excess clothing, cooling with cool water spray and encouraging oral fluids.

Heatstroke is defined by central nervous system involvement, presenting as syncope, confusion or seizures, multiorgan failure and extreme hyperthermia $\left(>40^{\circ} \mathrm{C}\right)$. Heatstroke is often precipitated by vigorous exercise in a hot and humid environment (exertional heatstroke); however, it is also increasingly observed in the elderly, children and those with chronic illness during extreme heat events worldwide (classical heatstroke). Heatstroke is a medical emergency with a high mortality rate. The most important action for a casualty of heatstroke is to begin immediate cooling and to activate the EMS to transport the casualty to the hospital for advanced care. ${ }^{(1,21)}$ Although the current recommendation from ILCOR is immediate active cooling using whole body (from the neck down) water immersion in water that is $1^{\circ} \mathrm{C}-26^{\circ} \mathrm{C}$ until the core temperature falls below $39^{\circ} \mathrm{C}$, when water immersion is not available, any other active or passive cooling technique (e.g. remove outer clothing, provide space for airflow, cooling 
with tepid sponging in the neck, armpits, groin, etc) should be initiated..$^{(1,44-46)}$ As heatstroke casualties may not be able to swallow safely, one should not force them to drink.

\section{Ingested poisons}

Limit further access to the ingested poison by the casualty. The first aider should activate the EMS immediately. Do not try to induce vomiting or administer anything by mouth for any ingested poison because it may be harmful. There is no role of dilution with water or activated charcoal as a first aid measure. ${ }^{(21)}$

\section{TRAUMA URGENCIES Bleeding}

Control of bleeding is an important skill in first aid and one of the most likely interventions to benefit survival. Blood loss is responsible for $30 \%-40 \%$ of trauma mortality, and of these deaths, $33 \%-56 \%$ occur during the prehospital period. ${ }^{(47,48)}$

Experience and evidence from military and civilian studies suggest that in life-threatening external extremity bleeding that is amenable to the application of a tourniquet, first aiders should use a tourniquet rather than direct manual pressure or dressing alone. If a tourniquet is not immediately available, direct manual pressure should be applied to control life-threatening external bleeding from an extremity until a tourniquet (commercial or improvised) can be applied. There is little evidence to recommend any one particular design of commercially available tourniquet over another. We encourage professional first aid organisations and individual first aiders to use commercial tourniquets. While SRFAC will continue to teach improvised tourniquets as a foundational skill (in the event that a commercial one is unavailable or the first aider is unfamiliar), familiarity of use by the first aider is the most important point. ${ }^{(1,49)}$

Direct pressure is a quick and effective method that can be easily performed by all first aiders, ${ }^{(50-53)}$ particularly if the bleeding site is not amenable to tourniquet use. Firm pressure maintained for a prolonged duration is necessary for successful control of bleeding. If it is not possible to provide continuous manual pressure, an elastic bandage wrapped over gauze should be applied with pressure. ${ }^{(54-57)}$ Compression of proximal 'pressure points' is not recommended, as this method does not account for collateral flow or back flow. ${ }^{(58)}$ Although haemostatic dressings have been used successfully by the military and regularly in hospital settings, they are not yet available to first aiders.

\section{Head injury}

The mechanisms and effects of head injury are varied and subtle. First aiders should be able to recognise the mechanisms of injury leading to traumatic brain injury, as well as recognise casualties with significant head injury. Failure to do so can have long-term adverse, even fatal, consequences. ${ }^{(59)}$

Many of the mechanisms leading to significant head injury can also cause spinal injuries. Measures to ensure basic spinal protection should be in place. As scalp wounds can bleed profusely, pressure dressings may need to be applied. The casualty also needs to be reviewed in a hospital setting to rule out any intracranial injury. Therefore, we recommend that any casualty with a head injury resulting in a change of level of consciousness, with progressive development of headache, nausea, vomiting, dizziness, unsteadiness, visual disturbance, confusion and amnesia (before or after the injury), to be evacuated to a hospital for evaluation by a doctor as soon as possible.(1)

\section{Spinal motion restriction}

Spinal injury after trauma should be suspected in the following situations: individuals aged $\geq 65$ years; driver, passenger or pedestrian in a motor vehicle, motorcycle or bicycle crash; fall from greater than standing height; altered sensation in the extremities; pain or tenderness in the neck or back; sensory deficit or muscle weakness involving the torso or upper extremities; intoxication or not being fully alert; other painful distracting injuries, especially of the head and neck; and children $\geq 2$ years with evidence of head or neck trauma. ${ }^{(21)}$

In such situations, we recommend that the first aider keep the casualty as still as possible till the arrival of the EMS, unless there are signs of imminent danger, in which case the first aider should swiftly and carefully remove the casualty. Manual in-line immobilisation by the first aider is effective in the reduction of spine motion during extrication and transfer. ${ }^{(1)}$ The application of cervical collars by a first aider is discouraged, as the literature consistently shows more potential harm than benefit. ${ }^{(60-66)}$

\section{Bites and stings}

Animal and human bites should be irrigated with copious amounts of running water with or without soap to reduce bacterial and viral contamination. ${ }^{(67-69)}$ Direct pressure is usually adequate to control bleeding.

Snakebites should be immobilised with a splint and triangular bandages. They may benefit from the application of a pressure immobilisation bandage around the entire length of the bitten extremity to decrease venom dissemination by slowing lymph flow. ${ }^{(21)}$ However, skill retention for proper application is poor among first aiders, ${ }^{(70)}$ and inappropriately tight bandages may cause damage to local tissues. There should not be any attempt to cut the wound or suck the venom. Irrigating the wound or washing and rubbing the bitten area encourages local and systemic spread of venom, and should, therefore, be avoided. Application of a tourniquet to snake-bitten limbs is not advised.

When a casualty has been stung by a jellyfish, the first aider needs to prevent further nematocyst discharge and provide pain relief to the casualty. Care should be taken when removing tentacles - they should not be compressed or smeared but should ideally be removed with tweezers. Liberal washing with vinegar (4\%-6\% acetic acid solution) for at least 30 seconds can inactivate the venom and prevent further envenomation from nematocyst discharge. ${ }^{(71-73)}$ For pain relief, jellyfish and other marine stings should be treated with hot water immersion (maximum $45^{\circ} \mathrm{C}$ ) for $20-30$ minutes. ${ }^{(74-78)}$ The risks of secondary burns from this treatment are real, and care should be taken to avoid scalding by avoiding excessive temperature or prolonged immersion; for every 30 minutes of immersion, there should 
be 30 minutes of rest and elevation. ${ }^{(79)}$ If pain persists beyond the second cycle, a doctor should attend to the casualty. Some jellyfish, including the box jellyfish, can administer potentially fatal stings. If the casualty is unresponsive and not breathing, the first aider should provide basic life support, if required. Otherwise, the basic principles of treatment hold true for box jellyfish as for less poisonous jellyfish.

Bee stings may occur in solitary or, occasionally, as a result of a swarm. It is important to remove stingers without further release of venom. This can be achieved with the edge of a card or tweezers. Cold compress will help with pain. Allergic reactions to bee stings are not rare and should be monitored.

Although scorpion stings account for up to 2,600 deaths annually worldwide, the geographic spread of deadly species does not extend to this part of Southeast Asia. Stings of local scorpion species will cause pain, swelling and blistering. ${ }^{(80)} \mathrm{A}$ similar effect is seen from stings of wasps, hornets and centipedes. Cold compress, analgesia and monitoring for allergic reaction and skin necrosis are the main courses of treatment. ${ }^{(81)}$

\section{Dental injuries}

A casualty should always seek medical consult following dental avulsion. Bleeding from an avulsed tooth socket can be controlled by pressing a damp compress against the open tooth socket and having the casualty bite on it. ${ }^{(1,2)}$ However, this should not be done if the casualty may swallow the compress. Immediate reimplantation of an avulsed tooth within an hour has the greatest chance of tooth survival. ${ }^{(82)}$ When caring for the avulsed tooth, touch it at the crown and not the root, and if the avulsed tooth is contaminated, rinse it under tap water for a maximum of ten seconds. ${ }^{(1,2)}$ Transport the avulsed tooth by wrapping it in a cling film or storing it temporarily in a small container with Hank's balanced salt solution, propolis or oral rehydration salt solution; if none of these options are available, cow's milk can be used. ${ }^{(1,2)}$

\section{EDUCATION}

There is evidence of skills decay within 12 months after training. ${ }^{(83)}$ Frequent training improves skills, confidence and willingness to perform first aid. Although SRFAC retains the two-yearly recertification guidelines for first aid as well as for life support courses, individuals who are likely to encounter situations where their skills are needed should consider more frequent retraining.

Morbidity and mortality from injury and illness have improved as a result of educational approaches such as online courses, certification programmes and public health campaigns. ${ }^{(84-86)}$ These approaches should focus on prevention, recognition and management of injury and illness, as well as development of training guidelines in the context of first aid settings (e.g. workplace, sports facility).

With the adoption of mobile technology and the COVID-19 pandemic as a catalyst, online learning has provided an alternative to traditional classroom learning. Theory lectures have been moved online, leaving face-to-face contact hours for handson practice and assessments that are supervised and observed by instructors. While we expect such a blended model to become a popular mode of learning, specific guidelines for online content delivery will need to be developed and refined.

\section{CONCLUSION}

While the aims of training and delivering first aid remain constant, the scientific and clinical bases are constantly evolving with new innovations and evidence. Therefore, it is important to update the first aid practice guidelines with consensus opinion and the latest evidence.

\section{REFERENCES}

1. Singletary EM, Zideman DA, Bendall JC, et al; First Aid Science Collaborators. 2020 international consensus on first aid science with treatment recommendations. Resuscitation 2020; 156:A240-A282.

2. Singletary EM, Charlton NP, Epstein JL, et al. Part 15: first aid: 2015 American Heart Association and American Red Cross guidelines update for first aid. Circulation 2015; 132(18 Suppl 2):S574-89.

3. Klein TA, Tadi P. EMS Scene Safety. In: StatPearls [Internet]. Treasure Island, FL: StatPearls Publishing, 2021.

4. Karpel JP, Aldrich TK, Prezant DJ, et al. Emergency treatment of acute asthma with albuterol metered-dose inhaler plus holding chamber: how often should treatments be administered? Chest 1997; 112:348-56.

5. Weiss SJ, Anand P, Ernst AA, Orgeron D, May WL. Effect of out-of-hospital albuterol inhalation treatments on patient comfort and morbidity. Ann Emerg Med 1994; 24:873-8.

6. Osmond $\mathrm{MH}$, Klassen TP. Efficacy of ipratropium bromide in acute childhood asthma: a meta-analysis. Acad Emerg Med 1995; 2:651-6.

7. Hermansen MN, Nielsen KG, Buchvald F, et al. Acute relief of exercise-induced bronchoconstriction by inhaled formoterol in children with persistent asthma. Chest 2006; 129:1203-9.

8. Amirav I, Yacobov R, Luder AS. Formoterol turbuhaler is as effective as salbutamol diskus in relieving adenosine-induced bronchoconstriction in children. J Aerosol Med 2007; 20:1-6.

9. Bentur L, Canny GJ, Shields MD, et al. Controlled trial of nebulized albuterol in children younger than 2 years of age with acute asthma. Pediatrics 1992; 89:133-7.

10. Emerman CL, Shade B, Kubincanek J. A controlled trial of nebulized isoetharine in the prehospital treatment of acute asthma. Am J Emerg Med 1990; 8:512-4.

11. Littner MR, Tashkin DP, Siegel SC, Katz R. Double-blind comparison of acute effects of inhaled albuterol, isoproterenol and placebo on cardiopulmonary function and gas exchange in asthmatic children. Ann Allergy 1983; 50:309-16.

12. Berger WE, Milgrom H, Skoner DP, et al. Evaluation of levalbuterol metered dose inhaler in pediatric patients with asthma: a double-blind, randomized, placebo- and active-controlled trial. Curr Med Res Opin 2006; 22:1217-26.

13. Politiek MJ, Boorsma M, Aalbers R. Comparison of formoterol, salbutamol and salmeterol in methacholine-induced severe bronchoconstriction. Eur Respir J 1999; 13:988-92.

14. van der Woude HJ, Postma DS, Politiek MJ, Winter TH, Aalbers R. Relief of dyspnoea by beta2-agonists after methacholine-induced bronchoconstriction. Respir Med 2004; 98:816-20.

15. Zideman DA, De Buck ED, Singletary EM, et al. European Resuscitation Council guidelines for resuscitation 2015 section 9. First aid. Resuscitation 2015; 95:278-87.

16. Singletary EM, Zideman DA, De Buck ED, et al. Part 9: first aid: 2015 international consensus on first aid science with treatment recommendations. Circulation 2015; 132(16 Suppl 1):S269-311.

17. Bruera E, de Stoutz N, Velasco-Leiva A, Schoeller T, Hanson J. Effects of oxygen on dyspnoea in hypoxaemic terminal-cancer patients. Lancet 1993; 342:13-4.

18. Philip J, Gold M, Milner A, et al. A randomized, double-blind, crossover trial of the effect of oxygen on dyspnea in patients with advanced cancer. J Pain Symptom Manage 2006; 32:541-50.

19. Longphre JM, Denoble PJ, Moon RE, Vann RD, Freiberger JJ. First aid normobaric oxygen for the treatment of recreational diving injuries. Undersea Hyperb Med 2007; 34:43-9.

20. Wijesinghe M, Perrin K, Healy B, et al. Pre-hospital oxygen therapy in acute exacerbations of chronic obstructive pulmonary disease. Intern Med J 2011; 41:618-22.

21. Markenson D, Ferguson JD, Chameides L, et al. Part 17: first aid: 2010 American Heart Association and American Red Cross guidelines for first aid. Circulation 2010; 122(18 Suppl 3):S934-46.

22. Randomised trial of intravenous streptokinase, oral aspirin, both, or neither among 17,187 cases of suspected acute myocardial infarction: ISIS-2. ISIS-2 (Second International Study of Infarct Survival) Collaborative Group. Lancet 1988; 2:349-60.

23. Barbash IM, Freimark D, Gottlieb S, et al. Outcome of myocardial infarction 
in patients treated with aspirin is enhanced by pre-hospital administration. Cardiology 2002; 98:141-7.

24. Freimark D, Matetzky S, Leor J, et al. Timing of aspirin administration as a determinant of survival of patients with acute myocardial infarction treated with thrombolysis. Am J Cardiol 2002; 89:381-5.

25. Jabot J, Teboul JL, Richard C, Monnet X. Passive leg raising for predicting fluid responsiveness: importance of the postural change. Intensive Care Med 2009; 35:85-90.

26. Wong $\mathrm{DH}, \mathrm{O}^{\prime}$ Connor D, Tremper KK, et al. Changes in cardiac output after acute blood loss and position change in man. Crit Care Med 1989; 17:979-83.

27. Ballesteros-Peña S, Rodriguez Larrard A. Does the Trendelenburg position affect hemodynamics? A systematic review. Emergencias 2012; 24:143-50.

28. Lim SH, Wee FC, Chee TS. Basic cardiac life support: 2016 Singapore guidelines. Singapore Med J 2017; 58:347-53.

29. St John Ambulance, St Andrew's First Aid, British Red Cross. First Aid Manual. $10^{\text {th }}$ ed. London: DK, 2014

30. Freire-Tellado M, Navarro-Patón R, Pavón-Prieto MDP. Does lying in the recovery position increase the likelihood of not delivering cardiopulmonary resuscitation? Resuscitation 2017; 115:173-7.

31. van der Lende M, Surges R, Sander JW, Thijs RD. Cardiac arrhythmias during or after epileptic seizures. J Neurol Neurosurg Psychiatry 2016; 87:69-74.

32. Langan Y, Nashef L, Sander JW. Sudden unexpected death in epilepsy: a series of witnessed deaths. J Neurol Neurosurg Psychiatry 2000; 68:211-3.

33. DeToledo JC, Lowe MR. Seizures, lateral decubitus, aspiration, and shoulder dislocation: time to change the guidelines? Neurology 2001; 56:290-1.

34. Kenefick RW, O'Moore KM, Mahood NV, Castellani JW. Rapid IV versus ora rehydration: responses to subsequent exercise heat stress. Med Sci Sports Exerc 2006; 38:2125-31.

35. Michell MW, Oliveira HM, Kinsky MP, et al. Enteral resuscitation of burn shock using World Health Organization oral rehydration solution: a potential solution for mass casualty care. J Burn Care Res 2006; 27:819-25.

36. Barclay RL, Depew WT, Vanner SJ. Carbohydrate-electrolyte rehydration protects against intravascular volume contraction during colonic cleansing with orally administered sodium phosphate. Gastrointest Endosc 2002; 56:633-8.

37. Currell K, Urch J, Cerri E, et al. Plasma deuterium oxide accumulation following ingestion of different carbohydrate beverages. Appl Physiol Nutr Metab 2008; 33:1067-72.

38. Jeukendrup AE, Currell K, Clarke J, Cole J, Blannin AK. Effect of beverage glucose and sodium content on fluid delivery. Nutr Metab (Lond) 2009; 6:9.

39. Evans GH, Shirreffs SM, Maughan RJ. Postexercise rehydration in man: the effects of osmolality and carbohydrate content of ingested drinks. Nutrition 2009; 25:905-13.

40. Greenleaf JE, Jackson CG, Geelen G, et al. Plasma volume expansion with oral fluids in hypohydrated men at rest and during exercise. Aviat Space Environ Med 1998; 69:837-44

41. Maughan RJ, Leiper JB. Sodium intake and post-exercise rehydration in man. Eur J Appl Physiol Occup Physiol 1995; 71:311-9.

42. Merson SJ, Maughan RJ, Shirreffs SM. Rehydration with drinks differing in sodium concentration and recovery from moderate exercise-induced hypohydration in man. Eur J Appl Physiol 2008; 103:585-94

43. Shirreffs SM, Taylor AJ, Leiper JB, Maughan RJ. Post-exercise rehydration in man: effects of volume consumed and drink sodium content. Med Sci Sports Exerc 1996; 28:1260-71.

44. Bouchama A, Knochel JP. Heat Stroke. N Engl J Med 2002; 346:1978-88.

45. Epstein Y, Yanovich R. Heatstroke. N Engl J Med 2019; 380:2449-59.

46. Bouchama A, Dehbi M, Chaves-Carballo E. Cooling and hemodynamic management in heatstroke: practical recommendations. Crit Care 2007; 11:R54.

47. Tannvik TD, Bakke HK, Wisborg T. A systematic literature review on first aid provided by laypeople to trauma victims. Acta Anaesthesiol Scand 2012; 56:1222-7.

48. Kauvar DS, Lefering R, Wade CE. Impact of hemorrhage on trauma outcome: an overview of epidemiology, clinical presentations, and therapeutic considerations. J Trauma 2006; 60(6 Suppl):S3-11.

49. Eilertsen KA, Winberg M, Jeppesen E, Hval G, Wisborg T. Prehospital tourniquets in civilians: a systematic review. Prehosp Disaster Med 2021; 36:86-94.

50. Naimer SA, Chemla F. Elastic adhesive dressing treatment of bleeding wounds in trauma victims. Am J Emerg Med 2000; 18:816-9.

51. Pillgram-Larsen J, Mellesmo S. [Not a tourniquet, but compressive dressing Experience from 68 traumatic amputations after injuries from mines]. Tidsskr Nor Laegeforen 1992; 112:2188-90. Norwegian.

52. Naimer SA, Nash M, Niv A, Lapid O. Control of massive bleeding from facial gunshot wound with a compact elastic adhesive compression dressing. Am Emerg Med 2004; 22:586-8.

53. Naimer SA, Anat N, Katif G; Rescue Team. Evaluation of techniques for treating the bleeding wound. Injury 2004; 35:974-9.

54. Beekley AC, Sebesta JA, Blackbourne LH, et al; $31^{\text {st }}$ Combat Support Hospital Research Group. Prehospital tourniquet use in Operation Iraqi Freedom: effect on hemorrhage control and outcomes. J Trauma 2008; 64(2 Suppl):S28-37.

55. King DR, van der Wilden G, Kragh JF Jr, Blackbourne LH. Forward assessment of 79 prehospital battlefield tourniquets used in the current war. J Spec Oper Med 2012; 12:33-8.

56. Lakstein D, Blumenfeld A, Sokolov T, et al. Tourniquets for hemorrhage control on the battlefield: a 4-year accumulated experience. J Trauma 2003; 54(5 Suppl):S221-5.

57. Kue RC, Temin ES, Weiner SG, et al. Tourniquet use in a civilian emergency medical services setting: a descriptive analysis of the Boston EMS experience. Prehosp Emerg Care 2015; 19:399-404.

58. Swan KG, Swan KG Jr, Ahearn M. Tourniquets, pressure points, and extremity hemorrhage. Mil Med 2012; 177:6-7.

59. Maroon JC, Mathyssek C, Bost J. Cerebral concussion: a historical perspective. Prog Neurol Surg 2014; 28:1-13.

60. Davies G, Deakin C, Wilson A. The effect of a rigid collar on intracranial pressure. Injury 1996; 27:647-9.

61. Hunt K, Hallworth S, Smith M. The effects of rigid collar placement on intracranial and cerebral perfusion pressures. Anaesthesia 2001; 56:511-3.

62. Mobbs RJ, Stoodley MA, Fuller J. Effect of cervical hard collar on intracranial pressure after head injury. ANZ J Surg 2002; 72:389-91.

63. Kolb JC, Summers RL, Galli RL. Cervical collar-induced changes in intracranial pressure. Am J Emerg Med 1999; 17:135-7.

64. Raphael JH, Chotai R. Effects of the cervical collar on cerebrospinal fluid pressure. Anaesthesia 1994; 49:437-9.

65. Stone MB, Tubridy CM, Curran R. The effect of rigid cervical collars on internal jugular vein dimensions. Acad Emerg Med 2010; 17:100-2.

66. Dodd FM, Simon E, McKeown D, Patrick MR. The effect of a cervical collar on the tidal volume of anaesthetised adult patients. Anaesthesia 1995; 50:961-3.

67. Callaham ML. Treatment of common dog bites: infection risk factors. JACEP 1978; 7:83-7

68. Kaplan MM, Cohen D, Koprowski H, Dean D, Ferrigan L. Studies on the local treatment of wounds for the prevention of rabies. Bull World Health Organ 1962; 26:765-75.

69. Dean DJ, Baer GM, Thompson WR. Studies on the local treatment of rabiesinfected wounds. Bull World Health Organ 1963; 28:477-86.

70. Norris RL, Ngo J, Nolan K, Hooker G. Physicians and lay people are unable to apply pressure immobilization properly in a simulated snakebite scenario. Wilderness Environ Med 2005; 16:16-21

71. Mianzan HW, Fenner PJ, Cornelius PF, Ramírez FC. Vinegar as a disarming agent to prevent further discharge of the nematocysts of the stinging hydromedusa Olindias sambaquiensis. Cutis 2001; 68:45-8

72. Burnett JW, Rubinstein H, Calton GJ. First aid for jellyfish envenomation. South Med J 1983; 76:870-2.

73. Loten C, Stokes B, Worsley D, et al. A randomised controlled trial of hot water (45 degrees C) immersion versus ice packs for pain relief in bluebottle stings. Med J Aust 2006; 184:329-33.

74. Nomura JT, Sato RL, Ahern RM, et al. A randomized paired comparison trial of cutaneous treatments for acute jellyfish (Carybdea alata) stings. Am J Emerg Med 2002; 20:624-6.

75. Yoshimoto CM, Yanagihara AA. Cnidarian (coelenterate) envenomations in Hawai'i improve following heat application. Trans R Soc Trop Med Hyg 2002; 96:300-3.

76. Cegolon L, Heymann WC, Lange JH, Mastrangelo G. Jellyfish stings and their management: a review. Mar Drugs 2013; 11:523-50.

77. Li L, McGee RG, Isbister G, Webster AC. Interventions for the symptoms and signs resulting from jellyfish stings. Cochrane Database Syst Rev 2013; (12):CD009688.

78. Atkinson PR, Boyle A, Hartin D, McAuley D. Is hot water immersion an effective treatment for marine envenomation? Emerg Med J 2006; 23:503-8.

79. Lewis CJ, Wood F, Goodwin-Walters A. latrogenic thermal burns secondary to marine sting treatment. J Burn Care Res 2020; 41:878-81.

80. Chippaux JP. Emerging options for the management of scorpion stings. Drug Des Devel Ther 2012; 6:165-73.

81. Fung HT, Lam SK, Wong OF. Centipede bite victims: a review of patients presenting to two emergency departments in Hong Kong. Hong Kong Med J 2011; 17:381-5.

82. Diangelis AJ, Andreasen JO, Ebeleseder KA, et al. International Association of Dental Traumatology guidelines for the management of traumatic dental injuries: 1. Fractures and luxations of permanent teeth. Dent Traumatol 2012; 28:2-12.

83. Greif R, Lockey A, Breckwoldt J, et al. European Resuscitation Council guidelines 2021: education for resuscitation. Resuscitation 2021; 161:388-407.

84. Skinner AM, Brown TL, Peat BG, Muller MJ. Reduced hospitalisation of burns patients following a multi-media campaign that increased adequacy of first aid treatment. Burns 2004; 30:82-5

85. Sunder S, Bharat R. Industrial burns in Jamshedpur, India: epidemiology, prevention and first aid. Burns 1998; 24:444-7.

86. Murad MK, Husum H. Trained lay first responders reduce trauma mortality: a controlled study of rural trauma in Iraq. Prehosp Disaster Med 2010; 25:533-9. 